\title{
Internet-delivered therapist-guided physical activity for mild to moderate depression: A randomized controlled trial
}

Objective:The main hypothesis, and the objective of the study, was to test if the participants allocated to the treatment group would show a larger reduction in depressive symptoms than those in the control group Methods:This study was a randomized nine week trial of an Internet-administered treatment based on guided physical exercise for Major Depressive Disorder (MDD). A total of 48 participants with mild to moderate depression, diagnosed using the Structured Clinical Interview for DSM-IV Axis I Disorders, were randomized either to a treatment intervention or to a waiting-list control group. The main outcome measure for depression was the Beck Depression Inventory-II (BDI-II), and physical activity level was measured using the International Physical Activity Questionnaire (IPAQ). The treatment program consisted of nine text modules, and included therapist guidance on a weekly basis.

Results:The results showed significant reductions of depressive symptoms in the treatment group compared to the control group, with a moderate between-group effect size (Cohen's $d$ $=0.67 ; 95 \%$ confidence interval: 0.09-1.25). No difference was found between the groups with regards to increase of physical activity level. For the treatment group, the reduction in depressive symptoms persisted at six months follow-up. Conclusions:Physical activity as a treatment for depression can be delivered in the form of guided Internet-based self-help. Trial Registration:The trial was registered at ClinicalTrials.gov (NCT01573130). 
1 Morgan Ström ${ }^{1}$

2 Carl-Johan Uckelstam ${ }^{1}$

3 Gerhard Andersson ${ }^{2,3}$

4 Peter Hassmén ${ }^{1}$

5 Göran Umefjord ${ }^{1}$

6 Per Carlbring ${ }^{4}$

$7 \quad{ }^{1}$ Department of Psychology, Umeå University, Sweden

$8{ }^{2}$ Department of Clinical Neuroscience, Karolinska Institutet, Stockholm, Sweden

$9{ }^{3}$ Department of Behavioural Sciences and Learning, Psychology, Swedish Institute for Disability

10 Research, Linköping University, Sweden

$11{ }^{4}$ Department of Psychology, Stockholm University, Sweden

12 Address of correspondence:

13 Per Carlbring

14 Department of Psychology, Stockholm University, Sweden

15 Tel: +49(0) 8163920

16 E-mail: per@carlbring.se 
The World Health Organization (WHO, 2001) predicts that depression will be one of the three most burdensome diseases in the world in 2020. With the advancement of communication technologies, new ways of providing and delivering psychological treatments have emerged ( $\underline{\mathrm{P}}$ Carlbring \& Andersson, 2006). The Internet has made it possible to reach people over great distances and provide psychological interventions to a vast number of patients at a low cost due to shorter treatment time per person (Andersson, 2009). Internet-delivered treatments also have the opportunity to increase accessibility for patients in remote geographical locations and to make support available for people who would not otherwise seek care (Newman, Szkodny, Llera, \& Przeworski, 2011). Furthermore, Internet-delivered treatments have the possibility of giving patients quick feedback and presentation of material in a step-by-step basis (Titov, 2011).

Currently, several studies have investigated the effects of Internet-delivered treatments for depression (Johansson \& Andersson, 2012). A large part of these studies have been based on cognitive behavior therapy (CBT) as the main theoretical framework, but there are exceptions (Johansson et al., 2012). Andersson and Cuijpers (2009) did a meta-analysis and found a significant difference between supported $(d=0.61)$ and unsupported $(d=0.25)$ depression treatments. In a more recent meta-analysis, a similar result was found by Richards and Richardson (2012). In addition, Johansson and Andersson (2012) found a strong and significant association between support and effect size with a Spearman correlation of $\rho=0.64$, indicating that more support yields larger effects.

Since the beginning of the 20th century, a large amount of research has been conducted concerning the effects of physical activity on clinical depression. Several studies have found treatment effects ranging in size from moderate to large (Barbour, Edenfield, \& Blumenthal, 2007; Silveira et al., 2013). However, there is still no consensus about the mechanisms of change that mediate reductions in depressive symptoms following psychotherapy (Lundh, 2009), and there is also limited knowledge regarding mediators of change following physical activity for depression, apart from the physiological effects of increased activity.

A meta-analysis by Davies et al. (2012) investigated the effects of Internet-delivered interventions to increase physical activity levels. The result showed generally small but statistically significant increases in physical activity levels in the 34 studies reviewed. To our knowledge, there are few studies, if any, on guided Internet-delivered physical activity for major depression.

The purpose of the present study was to evaluate a treatment for major depression based on physical exercise administered via the Internet. The treatment program was intended to decrease depressive symptoms and to motivate participants to increase their level of physical activity. The treatment group was compared to a waiting-list control group.

The main hypothesis, and the objective of the study, was to test if the participants allocated to the treatment group would show a larger reduction in depressive symptoms than those in the control group, as measured by the Beck Depression Inventory: Second Version (BDI-II; Beck, Epstein, Brown, \& Steer, 1988) and the Montgomery-Åsberg Depression Rating Scale: Short Version

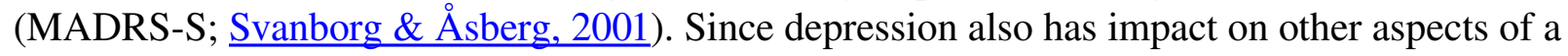


person's life we wanted to explore this further (Kennedy, Eisfeld, \& Cooke, 2001). Hence, it was hypothesized that participants in the treatment group would show larger reductions of anxiety symptoms as measured with the Beck Anxiety Inventory (BAI; Beck et al., 1988), and greater increases in levels of physical activity as measured with the International Physical Activity Questionnaire (IPAQ; Craig et al., 2003) compared to participants in the control group. Moreover, the authors expected that participants in the treatment group would show a larger increase in quality of life compared to the control, measured with the Quality of Life Inventory (QOLI; Frisch, Cornell, Villanueva, \& Retzlaff, 1992)

\section{Method}

Information about the study was advertised in a major Swedish newspaper, online with Google AdWords, and at an online service site containing information about ongoing research projects on Internet therapy. The participants were recruited between January and February 2012. The basic inclusion criteria in the study was mild to moderate major depression diagnosis and a sedentary lifestyle. Exclusion was based on the following criteria: subclinical depressive symptoms, severe depressive symptoms, dysthymia as a primary diagnosis, elevated suicide risk, high levels of physical activity prior to treatment, recent changes in medication and/or somatic illness making physical exercise inappropriate.

The eligibility screening process consisted of self-report questionnaires regarding depressive symptoms, anxiety, and level of physical activity, and a clinical interview via telephone to investigate the primary diagnoses of the participants. The screening questionnaires used were the MADRS-S, BAI, and IPAQ. The telephone interview was based on the Structured Clinical Interview for DSM-IV: Clinical version (SCID-I-CV; First, Gibbon, Spitzer, \& Williams, 1997). A full description of participant recruitment is included in Figure 1, and a demographic description of the participants at pre-treatment is presented in Table 1.

The study included 48 participants meeting the criteria for major depression. The participants were randomly allocated to the two groups, treatment or waiting list control, by a person independent of the research group using a true random number service on the Internet (www.random.org). Participants' levels of depression as well as anxiety, physical activity, and quality of life were measured at pre- and post-treatment, as well as at a 6-months follow-up. The study was conducted between February and April 2012, and the follow-up measurements were collected in October 2012.

The main outcome measure for the assessments of depression and depressive symptoms was the BDI-II with reported reliability estimates (coefficient $\alpha$ ) for Swedish samples between $\alpha=.88$ and $\alpha=.92$ (Per Carlbring et al., 2007). As a secondary measure of depression, we used the MADRS-S, which has a reported reliability estimate of $\alpha=.84$ (Fantino \& Moore, 2009). The psychometric properties of the Internet versions of these instruments have proved to be equivalent to the paper-and-pencil versions (Hollandare, Andersson, \& Engstrom, 2010). For evaluating changes in anxiety, physical activity, and quality of life, the BAI, IPAQ, and QOLI were administered; all of which showing satisfactory psychometric properties (Lindner, Andersson, Öst, \& Carlbring, in press; Ekelund et al., 2006). 


\section{Intervention}

The treatment used in this study was a guided self-help program administered through an Internet-based system. The program consisted of nine text modules developed by the authors, consisting of 72 pages in total. Participants were given one text module every Monday over nine weeks. At the end of each week, the therapists gave written feedback on home assignments included in the modules. Message exchange and the delivery of the treatment modules used were transmitted via an encrypted web-based system. Some material, such as the pedometer given participants in the treatment condition, and the written form of consent, were sent using the postal service. The purpose of the pedometer was for the participants to monitor their own physical activity in the form of walking, which was a part of the treatment program. The pedometers were used for motivational purposes alone and since participants had different ways of using them no data was collected in the study

The modules consisted of self-help texts about how to become more physically active (see Table 2). Each module ended with 3-5 essay questions where the participant was asked to report on the progress and the weekly planning of the exercise. The core principles of the program were inspired by Haase and coworkers (2010) and were intended to: 1) maximize the likelihood for participants to increase and maintain physical activity; 2) maximize the likelihood of participants remaining engaged in the program; 3) focus on the participants' preferences and needs, taking particular notice of the challenges faced by people with major depression; 4) promote physical activity in a broad sense in accordance with the WHO's guidelines for physical activity (Mendes, Sousa, \& Barata, 2011), including all types of activity in everyday life; 5) increase self-efficacy for physical activity; and 6) help participants to master challenges faced with when trying to get more active. The study was examined and approved by the regional ethical committee at Umeå, Sweden (2011-145-31 Ö), and is registered in Clinical Trials (NCT01573130).

\section{Statistical analysis}

The data were analyzed using the statistical programming language $\mathrm{R}$, version 3.0.0. Reproducible code can be found in the supplemental file (Progredi.R). Significance testing of group differences regarding demographic data in Table 1 and pre-treatment measurements was conducted using Welch's two sample t-test for continuous data and chi-2-tests for nominal data.

Differences between the groups in pre- and post-measurements were analyzed using a two-way mixed analysis of variance model (ANOVA), with treatment condition and time used as independent variables. Effect sizes were calculated using Cohen's $d$.

Data were analyzed using an intention-to-treat (ITT) approach. The response rate for all outcome measures was $100 \%$ (48 of 48) for pre- and post-treatment measurements, and $87.5 \%$ (21 of 24) for the 6-month follow-up. Due to the small number of missing data, we did not impute the missing data at 6-month follow-up, but used baseline carried forward as an estimate for the three 
missing data points. For ethical reasons the wait list received treatment immediately following the post assessment. Hence, there is no control group data at 6-month follow-up.

Participants who changed their medication or began psychological treatment during the study were considered unchanged in the analysis to control for effects from other treatments (treatment $\mathrm{n}=1$, control $\mathrm{n}=3, \mathrm{NS}$ ). Two participants gave inadequate answers on the IPAQ pre-treatment, and were therefore excluded from the analysis on that measure.

Clinically significant change on the main outcome measure, BDI-II, was calculated according to Jacobson and Truax (1991), with test-retest data from Sprinkle et al. (2002), and clinical cut-off scores in accordance with the BDI-II manual (Beck \& Steer, 1996). Reliable change (RC) was calculated with $95 \%$ confidence intervals.

\section{Results}

As evident from Table 1, participants were predominantly female (83\%), currently married or cohabiting (46\%), had attained college or higher-level education $(71 \%)$, and had previous experience of psychotherapy $(62 \%)$.

As evident from Table 1, the treatment- and the control group should be considered equal on all demographic characteristics with all $\mathrm{p}^{\prime} \mathrm{s}>.25$ (For sex $\chi^{2} 1=0.0, p=1.0$; age $t 40.66=0.25, p=$. 80 ; marital status $\chi^{2} 3=2.92, p=.40$; highest educational level $\chi^{2} 4=4.12, p=.40$; medication, $\chi^{2} 2$ $=5.34, p=.07$; and psychotherapy $\chi^{2} 2=0.0, p=1.0$ ).

During the treatment period of 9 weeks, 14/24 (58\%) of the participants in the treatment group completed all treatment modules (see Figure 1). The remaining participants did not complete the program within the given time frame, or dropped out. However, in compliance with the ITT principle, no participants were excluded from the statistical analyses due to low adherence or drop-out. Reasons given for not completing the program were that participants believed they did not have sufficient time for physical activity $(n=4)$, the program was perceived as non-effective $(n=2)$, or that changes in life events or sickness made it impossible for participants to complete the program $(n=1)$. Some participants ended the program without giving any reason for termination $(\mathrm{n}=3)$.

Table 2 includes means, effect sizes and tests of significance for group-, time-, and interaction effects on all outcome measures. No significant difference was found at pre-treatment between groups on all measures. Post-testing indicated that the treatment condition was superior to the control on both measures of depression (MADRS-S \& BDI-II), with significant interaction effects and medium effect sizes. No significant differences were found between groups on measures of anxiety (BAI), quality of life (QOLI), and physical activity level (IPAQ). Both groups achieved significant decreases in depressive symptoms and anxiety, and increases in quality of life and physical activity level during the study.

Follow-up after 6 months 
As seen in both Table 2 and Figure 2, the treatment effects were maintained at the 6-month follow-up. Actually, on the general measure of anxiety (BAI), there was a continued improvement between post and follow-up $\left(\mathrm{t}_{23}=2.51, \mathrm{p}<.05\right)$. The mean post to follow-up within-group effect size was $d=0.17$ with a low of 0.04 (IPAQ) and a high of $d=0.35$ (BAI).

Clinical significance

At post-treatment, 17/24 (70.8\%) of the participants in the treatment group were considered reliably improved on the main outcome measure, and 9/24 (37.5\%) as both reliably improved and recovered. In the control group, 8/24 (33.3\%) were considered improved, and 1/24 (4.2\%) reliably improved and recovered (Figure 3).

\section{Discussion}

The aim of this study was to develop and evaluate a treatment program for mild to moderate major depressive disorder based on physical activity administered via the Internet. The hypotheses were that participants in the treatment condition would have reduced their depressive and anxiety symptoms and at the same time increased levels of physical activity and quality of life more than participants in the control group.

Results showed a statistically significant interaction effect at post-testing favoring the treatment condition compared to the control condition, with a moderate between-groups effect size of Cohen's $d=0.67$ (95\% confidence interval: 0.09-1.25) on the main outcome measure of depression, BDI-II. The within-group effect size was large for the treatment group with Cohen's $d$ $=0.89(95 \%$ confidence interval: $0.67-1.92)$ and moderate for the control group with $d=0.62(95$ $\%$ confidence interval: $0.03-1.19)$.

The effects found in the current study are in line with efficacy outcomes from other wellestablished evidence-based psychological treatments. For example, Silveira et al. (Silveira et al., $\underline{2013}$ ) reviewed the effects of physical activity for depression and found an effect size of $d=0.61$ for depressive symptoms compared to the control in all the studies included in the analysis. In addition to this, Andersson and Cuijpers (Andersson \& Cuijpers, 2009) found a between-group effect size of $d=0.61$ for supported computerized CBT treatments for depression, with a majority being studies on Internet-delivered CBT.

However, results in this study showed no significant difference between the groups on secondary measures of anxiety, physical activity, and quality of life (BAI, IPAQ, and QOLI). A possible explanation for this could be the low statistical power of the study due to a small sample size of $\mathrm{N}$ $=48$. Calculations made prior to the study indicated that a sample size of $\mathrm{N}=80$ would be required to find significant interaction effects if they existed in the population. The main reason for the small sample size was in part the limited number of participants registering their interest in the study $(\mathrm{N}=159)$, and in part the large percentage of excluded participants $(69.8 \%)$. The main reason for this exclusion rate was high self-rated levels of physical activity at baseline for participants registered for the study. Also, these findings are in line with the results in a similar trial where no relation between reduced depressive symptoms and secondary measures such as changes in quality of life were found (Dozois, Dobson, \& Ahnberg, 1998). 
The most surprising findings were the non-significant interaction effect on IPAQ. Two explanations for these results should be considered. Firstly, a large number of the participants in the study showed moderate or high levels of physical activity at pre-treatment $(60.5 \%)$. This ceiling effect in the sample provided small opportunities for increased levels of physical activity. Ideally, only participants with a low level of physical activity should have been included in the study since those individuals were expected to gain most from the treatment. However, such a rigorous exclusion would have left few participants to the study. Secondly, the IPAQ has several issues in need of consideration. Ekelund et al. (Ekelund et al., 2006) found that people significantly overestimate their physical activity using the IPAQ compared to using an objective measure. This brings some uncertainty to the results found in this study. It is possible that people in the treatment condition overestimated their physical activity less at post-treatment, than people in the control condition, since the treatment included detailed monitoring of physical activity. Thirdly, data cleaning was needed due to unreasonable answers. This was done to answers from eight participants according to principles from the International Physical Activity Questionnaire Group (2005). This process may have led to misinterpretations of the intended answers of the respondents. Lastly, four participants gave incomprehensible answers to questions on the IPAQ, indicating misunderstandings of the instructions.

In summary, the findings in this study indicate that internet-administered therapist-guided physical activity can be an effective treatment for depressive symptoms for people with mild to moderate major depression, but there is no evidence of effectiveness in raising levels of physical activity or quality of life, nor reducing symptoms of anxiety. Since the effects found for depressive symptoms cannot be explained by changes in physical activity, questions are raised concerning the active ingredients in the treatment.

While Internet-delivered therapy has potential benefits there are also issues of potential concerns e.g., the risk of missing physical signs of depression such as agitation or retardation; difficulty identifying clients adequately for follow-up of increasingly suicidal patients, including involuntary treatment if required.

Some researchers state that there is no dose-response relationship between levels of physical activity and depressive symptoms (Kesaniemi et al., 2001). This implies that other aspects than the frequency, duration, and intensity of physical activity mediates changes in depressive symptoms. Considering this, it seems unlikely that improved fitness and related physiological changes account for reduced depressive symptoms in this study. Rather, it seems that other aspects of the treatment account for the obtained effects.

Firstly, earlier research has shown that self-help programs in which support is provided are more effective than programs without support (Spek et al., 2007; Palmqvist, Carlbring, \& Andersson, 2007). In this program, feedback based on motivational interviewing principles (cf. Miller \& Rollnick, 2002) was given each week. This could possibly explain the positive outcome to some extent. 
Research shows that behavioral activation is an effective treatment for depression (Dimidjian, Barrera, Martell, Munoz, \& Lewinsohn, 2011) which can be administered over the Internet (P. Carlbring, Hagglund, et al., 2013). The planning and monitoring of exercise could account for some of the positive outcome effect on depressive symptoms.

Thirdly, a reoccurring feature of the treatment was that participants set their goals independently. Participants were encouraged to set efficient goals every week and to achieve them. Studies have shown increased levels of self-efficacy in people striving for and achieving their goals (Biddle \& Fox, 1998). To obtain goals and to enhance self-efficacy for physical activity can be seen as positively reinforced behavior. According to the spiral model, based on the same principles as behavioral activation, this can be a way to break depressive patterns and inactivity (Waller \& Gilbody, 2009).

A pedometer was also sent to each participant in the treatment condition. The purpose was to increase adherence to the program and to maximize the likelihood of participants engaging in physical activity. However, it could be argued that the pedometer that was sent free of charge was simply a way of enhancing a possible placebo effect (Sliwinski \& Elkins, 2013).

A little more than half $(58 \%)$ of the participants in the treatment condition completed all nine text modules on time. This low adherence rate is a cause for concern, but is in line with earlier reviews of Internet-based treatment studies which found that just over half of the participants complete all sessions during the treatment period (Eysenbach, 2005).

All participants included in the study completed post-testing, which is uncommon for studies of this kind (Christensen \& Mackinnon, 2006). Usually, the last observation carried forward principle is used for missing data. Having a complete dataset for both pre- and post-testing for both conditions increases reliability and validity of the results. Since it is feasible that other active treatments influence outcome measures in this study, a conservative way of handling data was preferred.

There were significantly more females than males in the study. This is common for studies on depression, but should be considered as a limitation for the generalizability of the results. In addition, the mean age in the sample was high (Table 1), with only 10 participants under 40 years of age.

Future research could dismantle the different parts of the treatment, such as physical activity, therapist support, and self-efficacy to estimate to which extent they influence the outcome (cf. $\underline{\text { P. }}$ Carlbring, Lindner, et al., 2013). Studies should include objective measures of physical activity as well as measures of mediating factors to distinguish between active ingredients of the treatment.

This study has introduced a new, potentially effective Internet-based treatment for depression based on a physical activity intervention. The treatment program may be a valid alternative to traditional treatments for depression for people unwilling to use antidepressant medication or psychotherapy. Because of the Internet-delivered nature of the program, it may be considered cost-effective and not limited by large geographical distances (Hedman, Ljotsson, \& Lindefors, 
287 2012).

288 Acknowledgement:

289 Thank you to Lina Aittamaa, Linda Ek, Linda Westling, Mikael Granlund, Jessica Henriksson, and Linda

290 Ternedal for serving as therapists, and to Alexander Alasjö for web programming. 
Andersson, G. (2009). Using the Internet to provide cognitive behaviour therapy. Behaviour Research and Therapy, 47(3), 175-180.

Andersson, G., \& Cuijpers, P. (2009). Internet-based and other computerized psychological treatments for adult depression: a meta-analysis. Cogn Behav Ther, 38(4), 196-205. doi: $10.1080 / 16506070903318960$

Barbour, K. A., Edenfield, T. M., \& Blumenthal, J. A. (2007). Exercise as a treatment for depression and other psychiatric disorders: a review. J Cardiopulm Rehabil Prev, 27(6), 359-367. doi: 10.1097/01.HCR.0000300262.69645.95

Beck, A. T., Epstein, N., Brown, G., \& Steer, R. A. (1988). An inventory for measuring clinical anxiety: Psychometric properties. Journal of Consulting and Clinical Psychology, 56(6), 893-897.

Beck, A. T., \& Steer, R. A. (1996). Beck Depression Inventory. Manual, Svensk version (Swedish version). Fagernes, Norway: Psykologiförlaget $\mathrm{AB}$.

Biddle, S. J. H., \& Fox, K. R. (1998). Motivation for physical activity and weight management. International Journal of Obesity, 22, S39-S47.

Carlbring, P., \& Andersson, G. (2006). Internet and Psychological Treatment. How Well Can They Be Combined? Computers in Human Behavior, 22, 545-553.

Carlbring, P., Brunt, S., Bohman, S., Richards, J. C., Öst, L.-G., \& Andersson, G. (2007). Internet vs. Paper and Pencil Administration of Questionnaires Commonly Used in Panic/Agoraphobia research. Computers in Human Behavior, 23(3), 1421-1434.

Carlbring, P., Hagglund, M., Luthstrom, A., Dahlin, M., Kadowaki, A., Vernmark, K., \& Andersson, G. (2013). Internet-based behavioral activation and acceptance-based treatment for depression: A randomized controlled trial. Journal of Affective Disorders, 148(2-3), 331-337. doi: DOI 10.1016/j.jad.2012.12.020

Carlbring, P., Lindner, P., Martell, C., Hassmen, P., Forsberg, L., Strom, L., \& Andersson, G. (2013). The effects on depression of Internet-administered behavioural activation and physical exercise with treatment rationale and relapse prevention: study protocol for a randomised controlled trial. Trials, 14, 35. doi: 10.1186/1745-6215-14-35

Christensen, H., \& Mackinnon, A. (2006). The law of attrition revisited. J Med Internet Res, 8(3), e20; author reply e21. doi: 10.2196/jmir.8.3.e20

Craig, C. L., Marshall, A. L., Sjostrom, M., Bauman, A. E., Booth, M. L., Ainsworth, B. E., .. . Oja, P. (2003). International physical activity questionnaire: 12-country reliability and validity. Med Sci Sports Exerc, 35(8), 1381-1395. doi: 10.1249/01.MSS.0000078924.61453.FB

Davies, C. A., Spence, J. C., Vandelanotte, C., Caperchione, C. M., \& Mummery, W. K. (2012). Meta-analysis of internet-delivered interventions to increase physical activity levels. Int $J$ Behav Nutr Phys Act, 9, 52. doi: 10.1186/1479-5868-9-52

Dimidjian, S., Barrera, M., Jr., Martell, C., Munoz, R. F., \& Lewinsohn, P. M. (2011). The origins and current status of behavioral activation treatments for depression. Annu Rev Clin Psychol, 7, 1-38. doi: 10.1146/annurev-clinpsy-032210-104535

Dozois, D. J. A., Dobson, K. S., \& Ahnberg, J. L. (1998). A psychometric evaluation of the Beck Depression Inventory - II. Psychological Assessment, 10(2), 83-89. doi: Doi 10.1037/10403590.10.2.83 
Ekelund, U., Sepp, H., Brage, S., Becker, W., Jakes, R., Hennings, M., \& Wareham, N. J. (2006). Criterion-related validity of the last 7-day, short form of the International Physical Activity Questionnaire in Swedish adults. Public Health Nutrition, 9(2), 258-265. doi: Doi 10.1079/Phn2005840

Eysenbach, G. (2005). The law of attrition. J Med Internet Res, 7(1), e11. doi: v7e11 [pii] 10.2196/jmir.7.1.e11

Fantino, B., \& Moore, N. (2009). The self-reported Montgomery-Asberg Depression Rating Scale is a useful evaluative tool in Major Depressive Disorder. BMC Psychiatry, 9, 26. doi: 10.1186/1471-244X-9-26

First, M. B., Gibbon, M., Spitzer, R. L., \& Williams, J. B. W. (1997). Structured clinical interview for DSM-IV Axis I Disorders (SCID-I). Washington, D.C.: American Psychiatric Press.

Frisch, M. B., Cornell, J., Villanueva, M., \& Retzlaff, P. J. (1992). Clinical validation of the Quality of Life Inventory. A measure of life satisfaction for use in treatment planning and outcome assessment. Psychological Assessment, 4(1), 92-101.

Haase, A. M., Taylor, A. H., Fox, K. R., Thorp, H., \& Lewis, G. (2010). Rationale and development of the physical activity counselling intervention for a pragmatic TRial of Exercise and Depression in the UK (TREAD-UK). Mental Health and Physical Activity, 3(2), 85-91. doi: http://dx.doi.org/10.1016/j.mhpa.2010.09.004

Hassmén, P., \& Hassmén, N. (2005) Hälsosam motion. Stockolm: Sisu idrottsböcker.

Hedman, E., Ljotsson, B., \& Lindefors, N. (2012). Cognitive behavior therapy via the Internet: a systematic review of applications, clinical efficacy and cost-effectiveness. Expert Rev Pharmacoecon Outcomes Res, 12(6), 745-764. doi: 10.1586/erp.12.67

Hayes, S. C., Luoma, J. B., Bond, F. W., Masuda, A. \& Lillis, J. (2006) Acceptance and Commitment Therapy: Model, processes and outcomes. Behaviour Research and Therapy, 44 (1) , 1-25.

Hollandare, F., Andersson, G., \& Engstrom, I. (2010). A comparison of psychometric properties between internet and paper versions of two depression instruments (BDI-II and MADRSS) administered to clinic patients. J Med Internet Res, 12(5), e49. doi: 10.2196/jmir.1392 International Physical Activity Questionnaire Group. (2005). Guidelines for the data processing and analysis of the "International Physical Activity Questionnaire. http://www.ipaq.ki.se/scoring.pdf

Jacobson, N. S., \& Truax, P. (1991). Clinical significance: A statistical approach to defining meaningful change in psychotherapy research. Journal of Consulting and Clinical Psychology, 59(1), 12-19.

Johansson, R., \& Andersson, G. (2012). Internet-based psychological treatments for depression. Expert Rev Neurother, 12(7), 861-869; quiz 870. doi: 10.1586/ern.12.63

Johansson, R., Ekbladh, S., Hebert, A., Lindstrom, M., Moller, S., Petitt, E., . . Andersson, G. (2012). Psychodynamic Guided Self-Help for Adult Depression through the Internet: A Randomised Controlled Trial. PLoS One, 7(5). doi: ARTN e38021

DOI 10.1371/journal.pone.0038021 Kennedy, S. H., Eisfeld, B. S., \& Cooke, R. G. (2001). Quality of life: an important dimension in assessing the treatment of depression? J Psychiatry Neurosci, 26 Suppl, S2328 . 
Kesaniemi, Y. K., Danforth, E., Jr., Jensen, M. D., Kopelman, P. G., Lefebvre, P., \& Reeder, B. A. (2001). Dose-response issues concerning physical activity and health: an evidence-based symposium. Med Sci Sports Exerc, 33(6 Suppl), S351-358.

Lindner, P., Andersson, G., Öst, L.-G., \& Carlbring, P. (in press). Validation of the Internetadministered Quality of Life Inventory (QOLI) in different psychiatric conditions. Cognitive Behaviour Therapy.

Lundh, L. G. (2009). What makes therapy work? A multifaceted question. Cogn Behav Ther, 38 Suppl 1, 3-7. doi: 10.1080/16506070902981503

Mendes, R., Sousa, N., \& Barata, J. L. (2011). [Physical activity and public health: recommendations for exercise prescription]. Acta Med Port, 24(6), 1025-1030.

Miller, W. R., \& Rollnick, S. (2002). Motivational interviewing: preparing people for change. New York: Guilford Press.

Newman, M. G., Szkodny, L. E., Llera, S. J., \& Przeworski, A. (2011). A review of technologyassisted self-help and minimal contact therapies for anxiety and depression: is human contact necessary for therapeutic efficacy? Clin Psychol Rev, 31(1), 89-103. doi: 10.1016/j.cpr.2010.09.008

Newnham, E. A., Hooke, G. R., \& Page, A. C. (2010). Progress monitoring and feedback in psychiatric care reduces depressive symptoms. J Affect Disord, 127(1-3), 139-146. doi: 10.1016/j.jad.2010.05.003

Palmqvist, B., Carlbring, P., \& Andersson, G. (2007). Internet-delivered treatments with or without therapist input: does the therapist factor have implications for efficacy and cost? Expert Rev Pharmacoecon Outcomes Res, 7, 291-297.

Posternak, M. A., \& Zimmerman, M. (2007). Therapeutic effect of follow-up assessments on antidepressant and placebo response rates in antidepressant efficacy trials: meta-analysis. Br J Psychiatry, 190, 287-292. doi: 10.1192/bjp.bp.106.028555

Prochaska, J. O., \& DiClemente, C. C. (1983). Stages and processes of self-change of smoking: toward an integrative model of change. Journal of consulting and clinical psychology, $51(3), 390-395$.

Richards, D., \& Richardson, T. (2012). Computer-based psychological treatments for depression: A systematic review and meta-analysis. Clinical Psychology Review, 32(4), 329-342. doi: DOI 10.1016/j.cpr.2012.02.004

Silveira, H., Moraes, H., Oliveira, N., Coutinho, E. S., Laks, J., \& Deslandes, A. (2013). Physical exercise and clinically depressed patients: a systematic review and meta-analysis. Neuropsychobiology, 67(2), 61-68. doi: 10.1159/000345160

Sliwinski, J., \& Elkins, G. R. (2013). Enhancing placebo effects: insights from social psychology. Am J Clin Hypn, 55(3), 236-248.

Spek, V., Cuijpers, P., Nyklicek, I., Riper, H., Keyzer, J., \& Pop, V. (2007). Internet-based cognitive behaviour therapy for symptoms of depression and anxiety: a meta-analysis. Psychol Med, 37(3), 319-328. doi: 10.1017/S0033291706008944

Sprinkle, S. D., Lurie, D., Insko, S. L., Atkinson, G., Jones, G. L., Logan, A. R., \& Bissada, N. N. (2002). Criterion validity, severity cut scores, and test-retest reliability of the Beck Depression Inventory-II in a university counseling center sample. Journal of Counseling Psychology, 49(3), 381-385. doi: Doi 10.1037//0022-0167.49.3.381 
422 Svanborg, P., \& Åsberg, M. (2001). A comparison between the Beck Depression Inventory (BDI)

423

424

425

426

427

428

429

430

431

432 and the self-rating version of the Montgomery Asberg Depression Rating Scale (MADRS). Journal of Affective Disorders, 64(2-3), 203-216.

Titov, N. (2011). Internet-delivered psychotherapy for depression in adults. Curr Opin Psychiatry, 24(1), 18-23. doi: 10.1097/YCO.0b013e32833ed18f

Waller, R., \& Gilbody, S. (2009). Barriers to the uptake of computerized cognitive behavioural therapy: a systematic review of the quantitative and qualitative evidence. Psychol Med, 39(5), 705-712. doi: 10.1017/S0033291708004224

World Health Organization. (2001). The World Health Report 2001-Mental Health: New Understanding, New Hope Retrieved from http://www.who.int/whr/2001/en/whr01 en.pdf 


\section{Figure 1}

\section{Flowchart of study participants}

Flowchart of study participants, point of random assignment, and drop-outs at each stage 


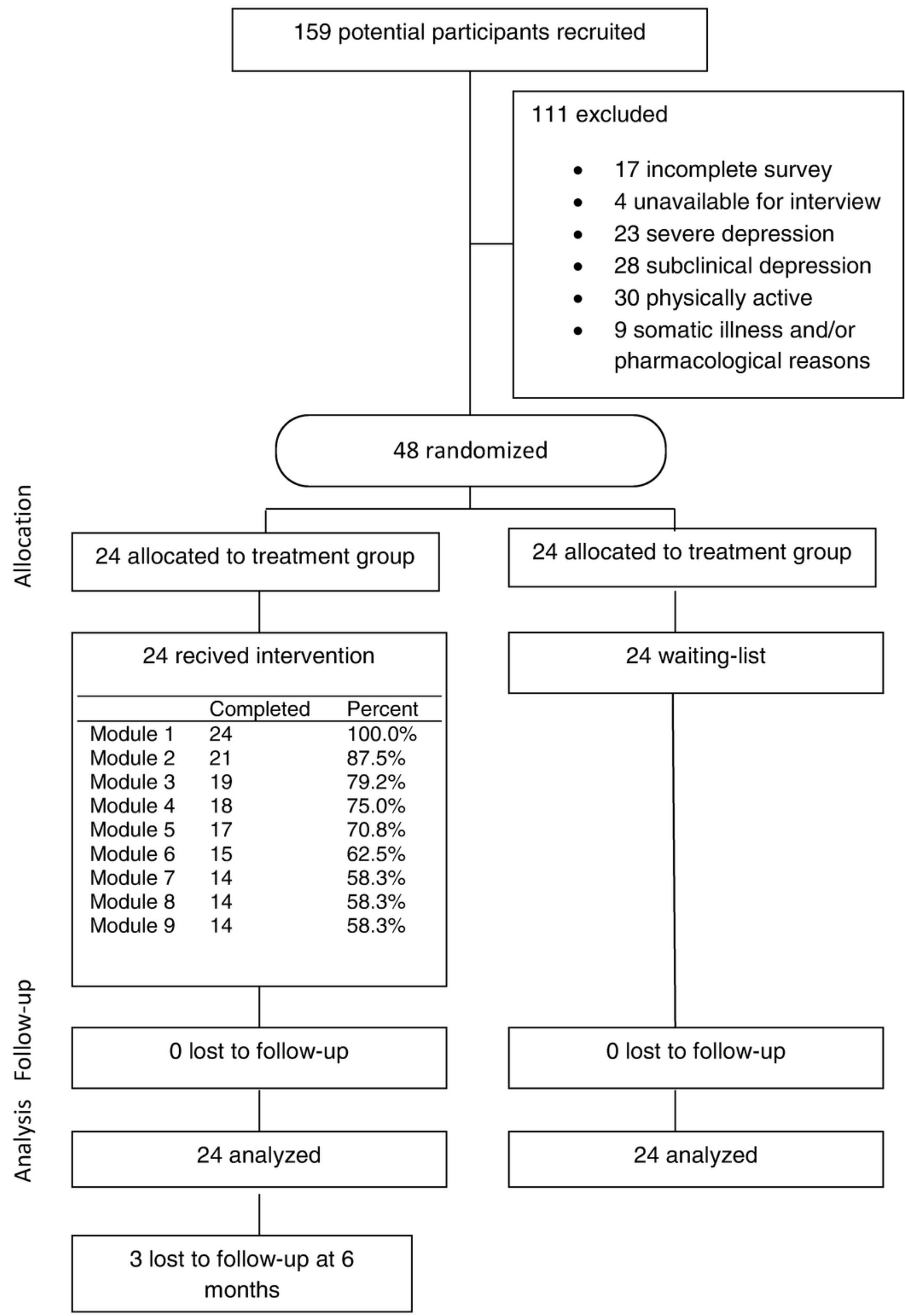




\section{Figure 2}

Mean scores and confidence intervals

The Beck Depression Inventory II (BDI-II) scores at pre, post and follow-up for the Treatment and the Control group including 95\% confidence intervals.

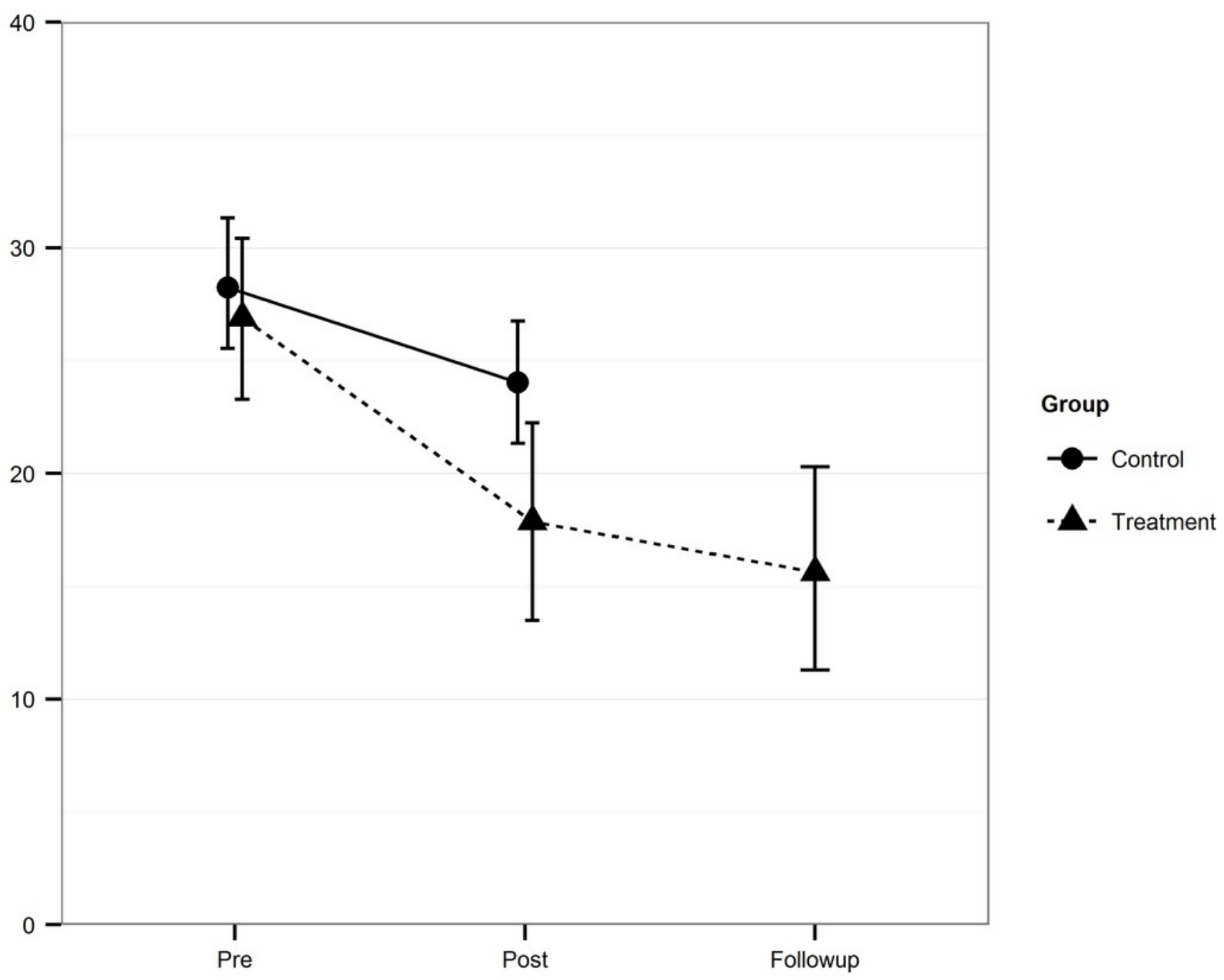




\section{Figure 3}

Clinically significant change on BDI-II post- treatment

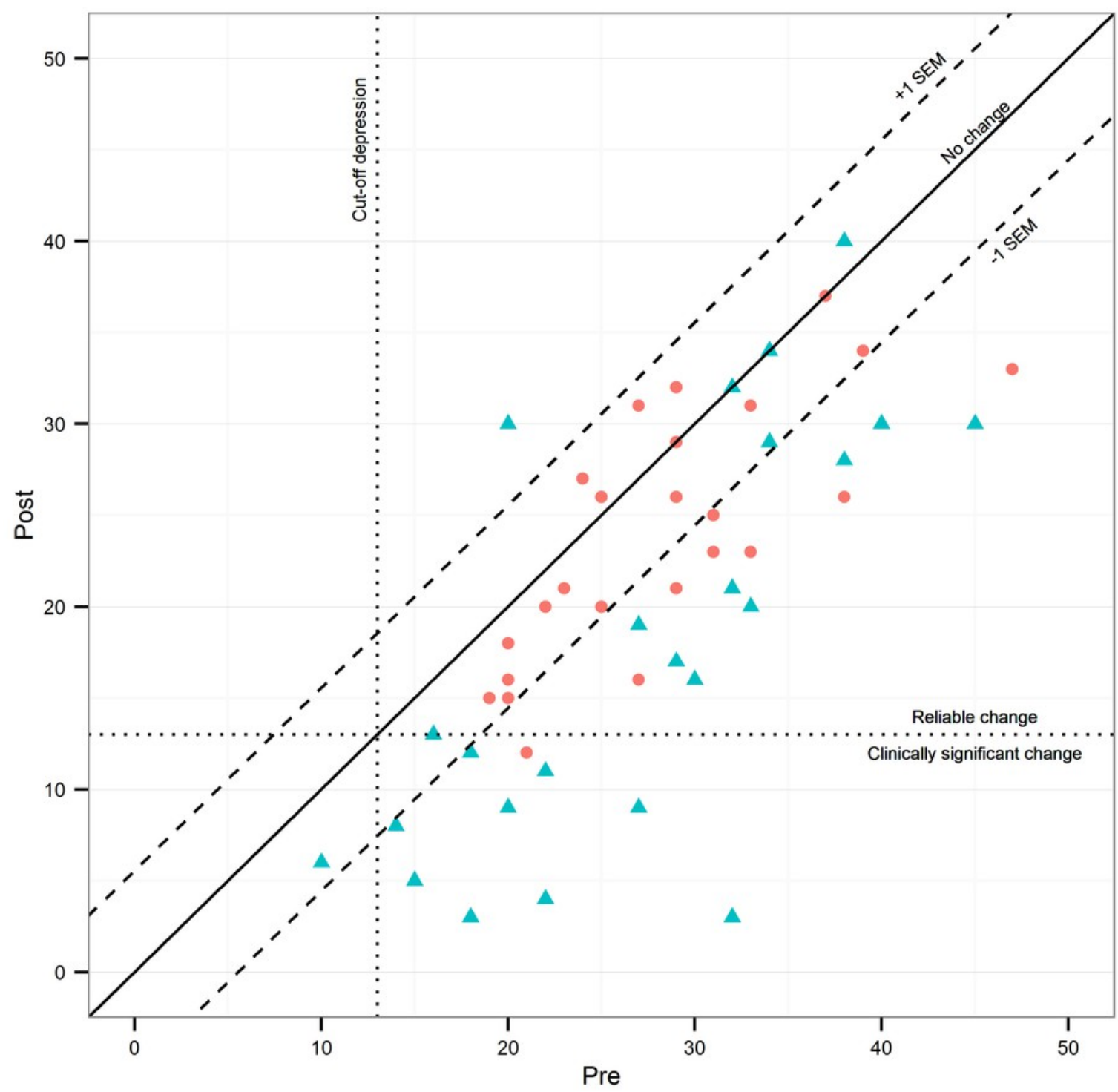

Group

- Control

$\Delta$ Treatment 


\section{Table 1 (on next page)}

Demographic description

Demographic description of the participants at pre-treatment 


\begin{tabular}{|c|c|c|c|c|c|c|c|c|}
\hline \multirow{2}{*}{$\begin{array}{l}\text { Sex } \\
\end{array}$} & & \multicolumn{2}{|c|}{ Treatment $(n=24)$} & \multicolumn{3}{|c|}{ Control $(n=24)$} & \multicolumn{2}{|c|}{ Total $(n=48)$} \\
\hline & & & & & & & & \\
\hline \multicolumn{2}{|l|}{ Female } & 20 & $(83.3 \%)$ & 20 & \multicolumn{2}{|c|}{$(83.3 \%)$} & 40 & $(83.3 \%)$ \\
\hline \multicolumn{2}{|l|}{ Male } & 4 & $(16.7 \%)$ & 4 & \multicolumn{2}{|c|}{$(16.7 \%)$} & 8 & $(16.7 \%)$ \\
\hline \multicolumn{9}{|l|}{ Age } \\
\hline \multicolumn{2}{|c|}{ Mean (SD) } & 48.8 & $(12.7)$ & 49.6 & \multicolumn{2}{|c|}{$(8.7)$} & 49.2 & \multirow[t]{2}{*}{$(10.7)$} \\
\hline Min-Ma & & $24-67$ & & $35-65$ & & & $24-67$ & \\
\hline \multicolumn{9}{|c|}{ Marital status } \\
\hline \multicolumn{2}{|c|}{ Married/Living together } & 13 & $(54.2 \%)$ & 9 & \multicolumn{2}{|c|}{$(37.5 \%)$} & 22 & $(45.8 \%)$ \\
\hline Living a & & 2 & $(8.3 \%)$ & 2 & \multicolumn{2}{|c|}{$(8.3 \%)$} & 4 & $(8.3 \%)$ \\
\hline Single & & 8 & $(33.3 \%)$ & 13 & \multirow{2}{*}{\multicolumn{2}{|c|}{$(54.2 \%)$}} & 21 & $(43.8 \%)$ \\
\hline Other & & 1 & $(4.2 \%)$ & 0 & & & 1 & $(2.1 \%)$ \\
\hline \multicolumn{9}{|c|}{ Highest educational level } \\
\hline \multicolumn{2}{|c|}{ Compulsory school } & 1 & $(4.2 \%)$ & 0 & \multirow{2}{*}{\multicolumn{2}{|c|}{$(12.5 \%)$}} & 1 & $(2.1 \%)$ \\
\hline Seconda & 10ol & 3 & $(12.5 \%)$ & 3 & & & 6 & $(12.5 \%)$ \\
\hline \multicolumn{2}{|c|}{ Vocational school } & 0 & & 3 & \multicolumn{2}{|c|}{$(12.5 \%)$} & 3 & $(6.3 \%)$ \\
\hline College/ & rsity (on-going) & 2 & $(8.3 \%)$ & 2 & \multicolumn{2}{|c|}{$(8.3 \%)$} & 4 & $(8.3 \%)$ \\
\hline \multicolumn{2}{|c|}{ College/university (compl.) } & 18 & $(75 \%)$ & 16 & \multicolumn{2}{|c|}{$(66.7 \%)$} & 34 & $(70.8 \%)$ \\
\hline \multicolumn{9}{|c|}{ Medication } \\
\hline None & 10 & $(41.7 \%)$ & 14 & \multicolumn{2}{|c|}{$(58.3 \%)$} & 24 & \multicolumn{2}{|r|}{$(50.0 \%)$} \\
\hline Earlier & 11 & $(45,8 \%)$ & 6 & \multicolumn{2}{|c|}{$(25.0 \%)$} & 17 & \multicolumn{2}{|r|}{$(35.4 \%)$} \\
\hline Present & 3 & $(12.5 \%)$ & 4 & (16. & & 7 & & $(14.6 \%)$ \\
\hline Psychot & & & & & & & & \\
\hline None & 9 & $(37.5 \%)$ & 9 & (37. & & 18 & & $(37.5 \%)$ \\
\hline Earlier & 15 & $(62.5 \%)$ & 15 & (62. & & 30 & & $(62.5 \%)$ \\
\hline Present & 0 & & 0 & & & 0 & & \\
\hline
\end{tabular}




\section{Table 2 (on next page)}

Content

Overview of content and home assignments of the Progredi intervention 


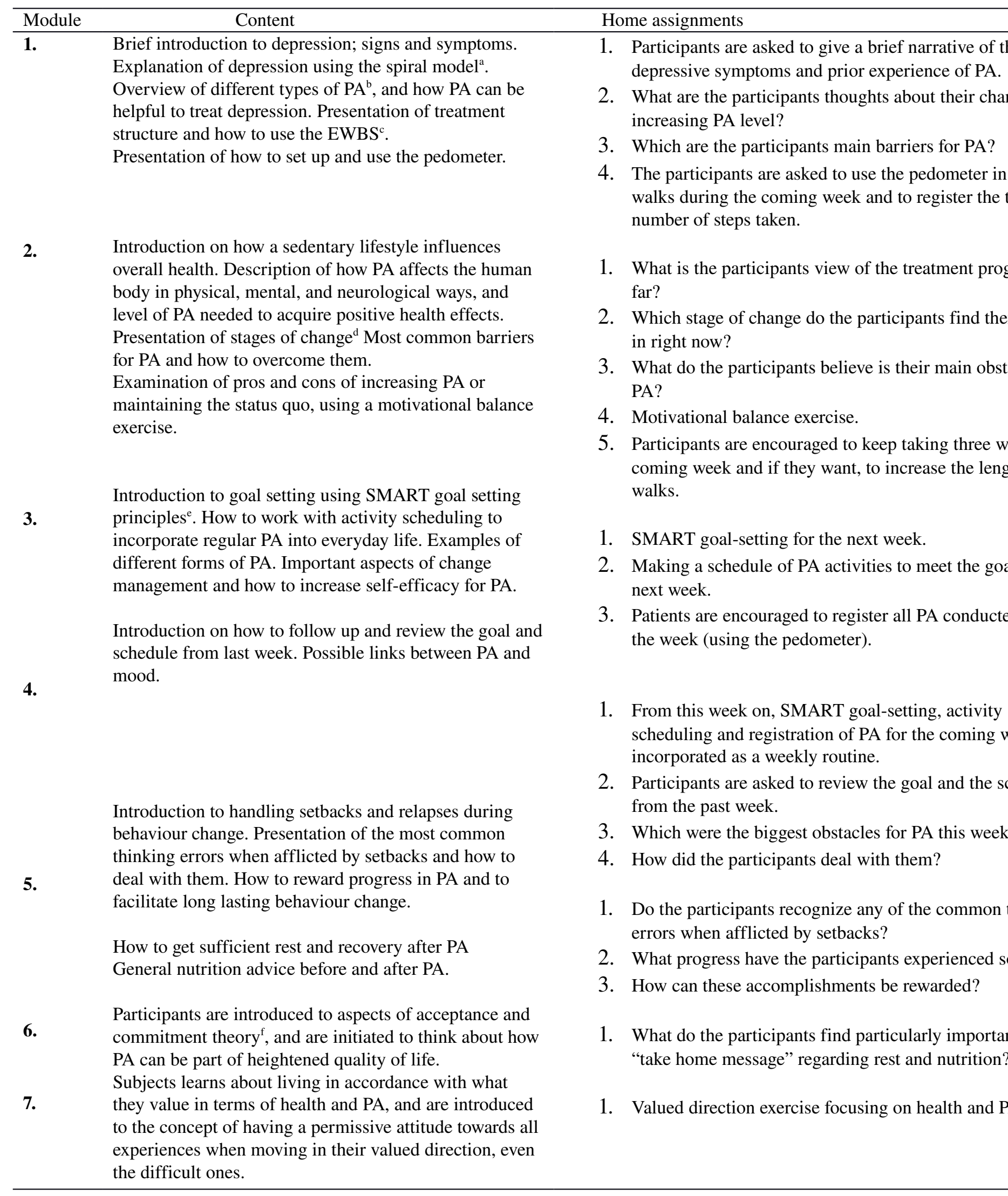


Mindfulness walking and how to incorporate acceptance

in the struggle to increase and maintain PA

How to maintain PA after the end of the treatment

8. program. Summary of the previous modules.

1. Participants are encouraged to do a mindfulness w exercise. What were their experiences?

9.

1. Participants are encouraged to answer the post-trea questionnaires administered over the Internet.

\author{
Note: ${ }^{\mathrm{a}}$ Haase and coworkers, 2010 \\ ${ }^{\mathrm{b}}$ physical activity \\ ${ }^{c}$ encrypted web-based system
}

d Prochaska \& DiClemente, 1983

e Hassmén \& Hassmén, 2005

${ }^{\mathrm{f}}$ Hayes, Luoma, Bond, Masuda \& Lillis, 2006 


\section{Table 3 (on next page)}

\section{Results}

Results at pre- and post-treatment for measures of depression, anxiety, physical activity, and quality of life. In addition, the 6-month follow-up for the Treatment group is reported 


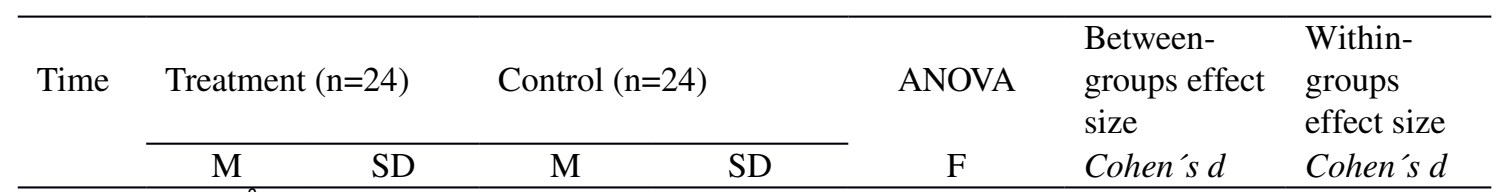

\begin{tabular}{lccccccl}
\hline \multicolumn{7}{l}{ Montgomery-Åsberg Depression Rating Scale: Self-Rated Version (MADRS-S) } \\
Pre & 23.54 & $(4.39)$ & 23.92 & $(3.87)$ & G: 3.02 & 0.62 & Tx: 1.30 \\
Post & 15.71 & $(7.54)$ & 20.38 & $(7.87)$ & T: $29.82^{* \star *}$ & & C: 0.58 \\
6-mo & 14.46 & $(7.63)$ & N/a & N/a & I: $4.25^{*}$ & &
\end{tabular}

Beck Depression Inventory: Second Version (BDI-II)

$\begin{array}{lccccccl}\text { Pre } & 26.92 & (9.30) & 28.25 & (7.08) & \text { G: } 2.52 & 0.67 & \text { Tx: } 0.89 \\ \text { Post } & 17.88 & (11.30) & 24.04 & (6.86) & \text { T: } 48.77^{\star \star *} & & \text { C: } 0.62 \\ \text { 6-mo } & 15.63 & (11.44) & \text { N/a } & \text { N/a } & \text { I: } 6.49^{\star} & & \end{array}$

Beck Anxiety Inventory (BAI)

$\begin{array}{lllcclll}\text { Pre } & 15.50 & (7.96) & 15.71 & (6.53) & \text { G: } 0.08 & 0.14 & \text { Tx: } 0.37 \\ \text { Post } & 12.92 & (6.36) & 13.71 & (5.27) & \text { T: } 9.29^{\star \star} & & \text { C: } 0.34 \\ \text { 6-mo } & 10.71 & (6.41) & \text { N/a } & \text { N/a } & \text { I: } 0.15 & & \end{array}$

International Physical Activity Questionnaire (IPAQ)

$\begin{array}{lccccccc}\text { Pre } & 778 & (695) & 953^{\mathrm{a}} & (670)^{\mathrm{a}} & \text { G: } 0.00 & 0.20 & \text { Tx: } 0.66 \\ \text { Post } & 1331 & (990) & 1143 & (918)^{\mathrm{a}} & \text { T: } 6.41^{*} & & \text { C: } 0.24 \\ \text { 6-mo } & 1282 & (1255) & \text { N/a } & \text { N/a } & \text { I: } 1.47 & & \end{array}$

Quality of Life Inventory (QOLI)

$\begin{array}{llllclll}\text { Pre } & -0.50 & (1.72) & -0.25 & (1.54) & \text { G: } 0.12 & 0.04 & \text { Tx: } 0.36 \\ \text { Post } & 0.16 & (1.99) & 0.23 & (1.47) & \text { T: } 11.49^{\star *} & & \text { C: } 0.33 \\ \text { 6-mo } & 0.33 & (2.00) & \text { N/a } & \text { N/a } & \text { I: } 0.28 & & \end{array}$

2 Note: $\mathrm{G}=$ Group effect; $\mathrm{T}=$ Time effect; $\mathrm{I}=$ Interaction effect; $\mathrm{Tx}=$ Treatment group; $\mathrm{C}=$ Control group; $\mathrm{N} / \mathrm{a}=$ not

3 available; $* * * \mathrm{p}<.001 ; * * \mathrm{p}<.01 ; * \mathrm{p}<.05 ;{ }^{\mathrm{a}} \mathrm{n}=22$ due to incomprehensible data 